\title{
VIDEO
}

\section{Hemostatic powder: a new ally in the management of postsphincterotomy bleeding}

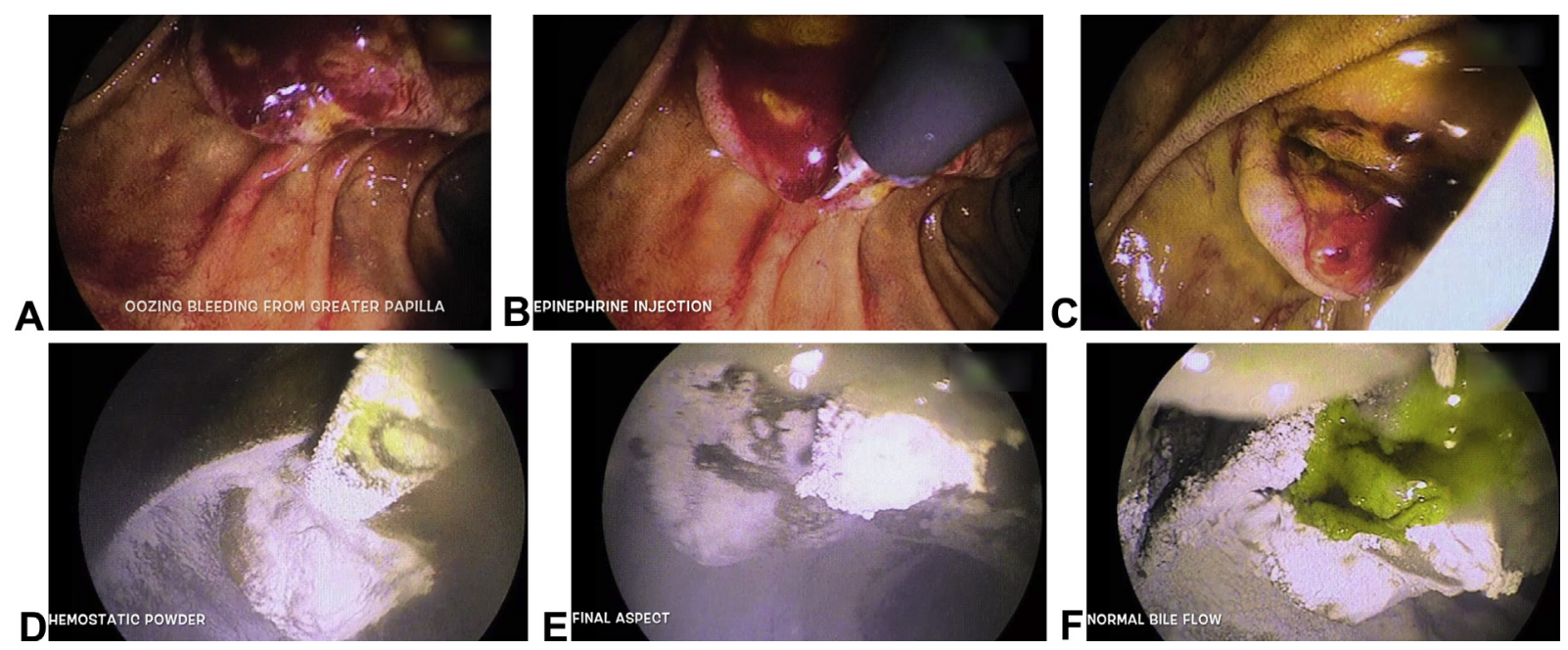

Figure 1. A, Oozing bleeding from sphincterotomy site. B, Epinephrine injection. C, Bleeding after epinephrine injection. D, Hemospray application. E, Final aspect. F, Normal bile flow after hemostatic powder application.

ERCP with sphincterotomy is the criterion standard treatment for the management of choledocholithiasis because it has low morbidity and mortality rates and excellent outcomes; however, adverse events are not uncommon.

Postsphincterotomy bleeding has an estimated incidence of less than $2 \%$, but it represents a serious adverse event of ERCP. The management of postsphincterotomy bleeding is challenging, and the main therapeutic modality is endoscopic treatment. The most commonly performed hemostatic procedure is epinephrine injection, which is effective in most cases. Nevertheless, some cases demand combined therapy. It is known that endoscopic clipping with the use of a side-view endoscope is a laborious procedure; therefore, the development of new hemostatic procedures is imperative.

Hemospray (Cook Medical, Winston-Salem, NC) is a new endoscopic accessory and consists of a mineral powder that absorbs water when applied to an actively bleeding lesion, forming a mechanical barrier over the bleeding site. We offer a video in which Hemospray application successfully controlled postsphincterotomy bleeding.

A 69-year-old man was referred to our department with a diagnosis of choledocholithiasis. ERCP confirmed the latter, and sphincterotomy, followed by calculi extraction, was successfully performed. However, the patient experienced melena 2 days later, and his hemoglobin fell from $17.0 \mathrm{~g} / \mathrm{dL}$ to $12.5 \mathrm{~g} / \mathrm{dL}$. A new duodenoscopy identified oozing bleeding from the sphincterotomy site. Epinephrine injection failed to control the hemorrhage, and we opted to complement the treatment with Hemospray application, which successfully achieved hemostasis (Fig. 1A-F; Video 1, available online at www.VideoGIE. org). The patient experienced neither pancreatitis nor other bleeding episodes during hospitalization and was discharged 2 days later.

This hemostatic powder has shown excellent outcomes in the context of upper-GI bleeding, with a high rate of immediate hemostasis (96.5\%). Our initial experiences have been very positive, especially when bleeding is severe and located at unfavorable clipping sites.

Even though a recent article (Moosavi et al, Endoscopy 2013;45:E130) reported a case of transient obstruction of the biliary orifice after Hemospray application, our patient did not experience any kind of biliary impairment. On the basis of this report, we do not consider periampular hemorrhage to be a contraindication for the use of Hemospray. Nevertheless, comparative studies are still needed to enable a correct assessment of the hemostatic capability of Hemospray and of related adverse events. 


\section{DISCLOSURE}

All authors disclosed no financial relationships relevant to this publication.

Felipe lankelevich Baracat, MD, Caio Vinicius Tranquillini, MD, Vítor Ottoboni Brunaldi, MD, Renato Baracat, MD, Eduardo Guimarães Hourneaux de Moura,
MD, PhD, Gastrointestinal Endoscopy Unit, Gastroenterology Department, University of São Paulo, São Paulo, Brazil

Copyright (c) 2017 American Society for Gastrointestinal Endoscopy. Published by Elsevier Inc. This is an open access article under the CC BY-NC-ND license (http://creativecommons.org/licenses/by-nc-nd/4.0/).

http://dx.doi.org/10.1016/j.vgie.2017.07.002 